\title{
A Brief Review on Developing Creative Thinking in Young Children by Mind Mapping
}

\author{
Wang, Wen-Cheng \\ Department of Business Management \\ Hwa Hsia Institute of Technology, Taiwan \\ 111 Gong Jhuan Rd., Chung Ho, Taipei, Taiwan, R.O.C \\ Tel: 886-2-8941-5022Ｅ-mail:wcwang@cc.hwh.edu.tw \\ Lee, Chung-Chieh \\ Department of Senior Citizen Service Management \\ Chia Nan University of Pharmacy \& Science, Tainan, Taiwan, R.O.C \\ Tel: 886-6-266-4911 E-mail:suprapeter1970@yahoo.com.tw \\ Chu, Ying-Chien \\ Department of Tourism and Leisure \\ National Penghu University, Taiwan \\ 300 Liu-Ho Rd., Makung city, Penghu, Taiwan, R.O.C \\ Tel: 886-6-926-4115 E-mail:verna323@npu.edu.tw
}

\begin{abstract}
Mind mapping is a presentation form of radiant thinking, utilizing lines, colors, characters, numbers, symbols, image, pictures or keywords, etc. to associate, integrate and visualize the learned concept and evoke brain potential. Through mind maps, one's attention, coordination ability, logic, reasoning, thinking, analyzing, creativity, imagination, memory, ability of planning and integration, speed reading, character, number, visuality, hearing, kinesthetic sense, sensation, etc. are significantly enhanced. "Picture" is not limited by nationality and language and is the best tool for young children to explore new things and learning. Because pictorial representation is one of the most primal human traits and drawing ability is better than writing ability in young children, learning and expressing through mind mapping prevents difficulties of writing, grammar and long description in children. Thus, this study reviews related researches to figure out whether mind mapping can be applied by young children to develop their creative thinking.
\end{abstract}

Keywords: Mind Mapping, Mind Maps, Young Children, Creativity, Radiant Thinking

\section{Background and Motivation}

Generally, words are used as tool of thinking by human. However, the ability of expressing in young children is not mature. It is better for children to express what they exactly feel via non-verbal pictures, charts, concept map and semantic network. "Picture" is not limited by nationality and language and is the best tool for young children to explore new things and learning. Here another point made by Arnheim seems provocative: Every picture is a statement. The picture does not present the object itself but a set of propositions about the object; or, if you prefer, it presents the object as a set of propositions (Arnheim, 1969). Through browsing concrete picture, young children are able to describe its content or even draw the content. "Mind map" can be seen as a product of memory. Mind mapping, Morning Pages, and Brainstorming are a few such tools that help one to collect and organize their creative output (Gino et al, 2004). Left brain manages the regular, ordered and linear logics, such as process of drawing, while right brain manages observation and sensation on features of objects, thinking on creativity, such as image, space, affection, etc. According to Filippakopoulou and Nakos (2009), children are exposed to maps from an early age. Map understanding progresses slowly and gradually from easy to difficult concepts. Theories of children's spatial development, mainly deriving from psychological studies, have provided the theoretical basis for approaching the way children use maps. The results of three decades of theoretical and experimental studies offer insight into children's thinking as to how they handle information while using maps and also provide evidence regarding the development of concepts associated with the basic characteristics of 
maps. There is still a lot more to be said. Specialists on children and mapping persistently ask for map literacy, facing children as map users in the information technology era.

Previous studies have suggested that children's learning of the relation between number words and approximate numerosities depends on their verbal counting ability, and that children exhibit no knowledge of mappings between number words and approximate numerical magnitudes for number words outside their productive verbal counting range (Barth, Starra \& Sullivan, 2009). Tony Buzan (1997) considers that radiant thinking is the most natural way for brain to function, while mind mapping is the best visualization tool to reflect radiant thinking of brain and maximize brain potential. As a graphic knowledge representation tool, a mind map 500 diagrams key ideas in a topic area and demonstrates the relationships among them (Novak, 1998; Hill, 2004). Thus, this study explores whether mind mapping can be applied by young children.

\section{Theory and Practice of Mind Mapping}

Mind map is a presentation form of radiant thinking, utilizing lines, colors, characters, numbers, symbols, images, pictures or keywords, etc. to associate and integrate, visualize the learned concept and maximize brain potential. (Buzan \& Buzan, 1996) (Fig.1). Mind mapping developed by Tony Buzan (1960) is a learning tool that can maximize brain potential in radiant thinking. In fact, some stakeholders have stated that this form of evaluation has helped them more clearly present and explain the impact and sustainability of their programs (Mary \& Skye, 2009). Through the process of mind mapping, capability of analyzing, comprehending and memorizing information is enhanced. Through mind maps, one's attention, coordination ability, logic, reasoning, thinking, analyzing, creativity, imagination, memory, ability of planning and integration, speed reading, character, number, visuality, hearing, kinesthetic sense, sensation, etc. are significantly enhanced because mind map organizes large amount of information systematically.

Mind map is a useful key adopting association skill and utilizing pictures to express the thoughts to maximize brain potential. It is a skill to develop the whole brain, applying characters, images, numbers, logics, rhythm, colors and unique observation method, providing a limitedless and free imaginary space to the brain. Briefly, mind map is a map for the brain (Buzan \& Buzan, 1996). Application of mind map is to construct "Divergent Thinking" in the brain. While applying mind mapping, ability of logical analyzing and reasoning of left brain and creative thinking and memory of right brain can be maximized.

Functions of mind map:

- Build a concept or viewpoint in a broader scope or topic.

- It provides a direction while planning or making decisions, helping users to collect and organize large amount information.

- It encourages users to solve problems by a new and creative way and thus enhances the effectiveness.

- It attracts and controls one's attention and thinking

- It makes observation, reading, thinking or memorizing interesting.

Steps of mind mapping:

I. Put the topic in the center. To start from the center conforms to the way of thinking of mind and also follows the natural rule.

II. It is better to use good-quality and blank A3 or A4 paper and put it horizontally.

III. Good-quality paper make one feel comfortable, while blank paper provides a limitedless and free thinking space.

IV. Application of image- It is better to be colorful and three-dimensional because it triggers thinking and strengthens memory more easily when it more close to the real-life context

V. Application of color-Different colors has different meanings for everyone

VI. Application of words-Words on each line represents a keyword, written tidy in the blank space and put only one vocabulary.

VII. The length of the line should equal to size of figure or length of sentence.

VIII. The line should be smooth and structured and are linked to each other

IX. The thickness of lines depends on the distance from the center. The nearer the line to the center, the thicker the line is. But the application can be adjusted according to different situations. 
$\mathrm{X}$. The structure and levels of mind map is radiant guided by association.

XI. The structure must be clear and ordered (clockwise or counter clockwise, depending on individual habit or topic).

XII. It is important that the style of mind maps should highlight the points and demonstrate self-style.

\section{Difference Between of Mind Map and Concept Map}

According to Novak \& Cañas (2008), concept maps are graphical tools for organizing and representing knowledge. Concept maps include concepts, usually enclosed in circles or boxes of some type, and relationships between concepts indicated by a connecting line linking two concepts. Words on the line referred to as linking words or linking phrases, specify the relationship between the two concepts. Figure 2 shows an example of a concept map that describes the structure of concept maps.

The primary feature of concept map is its level structure expressing relationship between concepts. The most general and inclusive are placed on the top of map, while the secondary ones are placed under the primary ones. Thus when seeking to understand an answer, situation or event, it is suggested to use specific questions to construct concept map and understand specific knowledge by structure of concept map. Another feature of concept map is its cross linkages. It is to express the relations of concepts in concept map. Cross linkage explicates how knowledge of specific domain linked to the other. Thus, a good concept map must contain good level structure and easy to search for the required information. It is better to include some events or examples for explicating the concept.

The followings are advantages of concept map application:

- It visually presents complicated knowledge structure and linkages between two knowledge points by simple graph

- It demonstrates one's knowledge of specific domain thoroughly and transparently.

- It is a tool organizing messages surrounding primary concepts.

- It increases comprehension toward concepts through defining causal relations, distinguishing level of concepts, organizing relationship of concepts and demonstrating other meaningful concept patterns.

- It allows learners to reflect the learning process over and over, predict possible behavior outcome and enhance learning effectiveness.

Steps of concept mapping:

I. Determine the center topic: Determine the center question, knowledge or concept to be explored via concept map and figure out concepts related to center topic via guiding of this topic and list out.

II. Sort the listed concepts: Place general, the most abstract and the most inclusive concepts on the top of map. There might be some difficulties while selecting the concept on the top of map. Reflecting on direction of center topic might be helpful for sorting concepts.

III. List out the rest of concepts according to the levels.

IV. Make a concept map: Place general, the most abstract and the most inclusive concepts on the top of map. There are only two or three inclusive concepts on the top of map.

V. Link these concepts with lines and put a conjunction on the line. These conjunctions must be able to clearly present the relationship between two concepts to make it a simple and valid thesis. When these concepts are linked and levels form, a corresponding meaning construction of knowledge, thesis and center topic can be found.

VI. Reorganize concept map: Increase or decrease concepts or alter relationship of upper level and lower level in the concept map.

VII. Figure out meaningful cross linkages in various branches of concepts and put conjunctions on the lines to present the relations, helping find a new relationship on knowledge of specific domain.

VIII. Detailed and concrete examples can be attached to these concepts by graphical symbols.

IX. For similar concepts, it can be presented by various structures of concept maps.

$\mathrm{X}$. Difference between mind map and concept map is that concept map emphasizes that linkage of network is changeable. Mind map combines color and picture. Its line is wavy and the concept is written on the line; while mind map emphasizes that secondary concepts surround primary concepts. Mind map is a kind of semantic 
mapping.

\section{Related works on application of mind mapping in developing creativity of young children}

Generally, words are used as tool of thinking by human and thus neglect to combine non-verbal pictures, chart, concept map and semantic network. "Mind mapping" is helpful for problem-solving process and deduction. Under visuality and brainstorming provided by pictures and characters, one is able to use both hands and brain. Thoughts are evoked while drawing. Messages obtained from the process can be attached to the concepts and trigger learning motivation. If students are taught to use these non-verbal symbols to think (so-called "Abstract Thinking") and being equipped with this ability, creativity, comprehension and problem-solving ability will be enhanced. The followings are analysis on results of related works:

Aydin and Balim (2009) study aims at enabling the students learn the concepts within the unit "Systems in Our Body", in the 6th grade Science and Technology lesson, based on the constructivist approach. Additionally, the mental constructions of the students were tried to be interpreted by making them prepare mind and concept maps by hand and in the computer environment during the lesson, regarding the subjects in the unit. The principles of preparing mind and concept maps were explained and examples of these maps prepared by the students were also included in this study. According to Dalke (1998), young 3-year-olds showed some ability to make and use maps but performed poorly on the false belief tests. Children were more likely to use an incorrect map to predict behavior if the represented object was missing instead of in a wrong location. Many children were also able to predict that someone who used an incorrect map would not "Find" the object. In particular, it would be useful for at least two individuals to go through the mind map independently to help ensure objectivity when reporting the number and strength of the relationships and connections listed (Cresswell, 1998). These results contradict Perner's hypothesis and suggest that representational skills develop gradually rather than appearing in a radical conceptual shift at age 4. Mundya and Gilmore (2009) used a novel task to assess children's mapping ability, they showed that children can map in both directions between symbolic and nonsymbolic numerical representations and that this ability develops between 6 and 8 years of age. Moreover, we reveal that children's mapping ability is related to their achievement on tests of school mathematics over and above the variance accounted for by standard symbolic and nonsymbolic numerical tasks. Chen (2007) examined the role of experience on 2.5- to 5-year-old children's discovery of spatial mapping strategies. With experience, 3- to 4-year-olds discovered a strategy for mapping corresponding locations that shared both featural and spatial similarities. When featural and spatial correspondences were placed in conflict, requiring children to negotiate both object-centered and location-centered mapping possibilities, 4- to 5-year-olds proved capable of discovering a novel mapping strategy, abandoning an ineffective strategy, and generalizing the acquired strategy across analogous tasks. It has been successfully used in community serving programs and could be similarly applied in youth serving agencies (Wells \& Arthur-Banning, 2007). Upon examining the mechanisms underlying developmental differences in strategy discovery and strategy change, the author observed that 3 key components contributed to the children's spatial mapping skills: encoding locations within each space, noticing a potential analogy between spaces, and detecting precise mapping correspondences. According to Atance and Meltzoff (2005), two experiments examine preschool-aged children's ability to anticipate physiological states of the self. One hundred and eight 3-, 4-, and 5-year-olds were presented with stories and pictorial scenes designed to evoke thought about future states such as thirst, cold, and hunger. They were asked to imagine themselves in these scenarios and to choose one item from a set of three that they would need. Only one of the items could be used to address the future state. In both experiments, developmental differences were obtained for correct item choices and types of verbal explanations. In Experiment 2, the performance of the 3- and 4-year-olds was negatively affected by introducing items that were semantically associated with the scenarios but did not address the future state, whereas the 5-year-olds' performance was not. According to the above exploration, it is known that mind mapping increases creativity of young children and allows cognition of children can be easily understood. With abundant colors, images, keywords or short sentences, such map integrates functions of right brain and left brain and facilitates thinking, memorizing, analyzing and triggering inspiration and allowing young children to learn via picture.

\section{Conclusions}

Mind mapping is a thinking method which stimulates thinking and helps integrate thoughts and information, and it is also a strategy of thinking visualizing concepts (Buzan \& Buzan, 1996). This mind mapping utilizes lines, colors, characters, numbers, symbols and pictures to quickly record information and thoughts, it clearly and easily record large amount of information or ideas which originally require magnitude of words to record on a mind map. The structure becomes open and organized, allowing one to organize a variety of information and evoke more new ideas. Finally, we propose some guidelines for later researches to improve course design of 
information education for young children. This allows one to find that picture is helpful for young children on learning and interaction. However, there are still some unanswered questions, such as: how to implement mind mapping in teaching, how to train the teachers to master this method, etc., need further investigation.

\section{References}

Arnheim, R. (1969). Visual Thinking. Berkeley, University of California Press.

Cristina M. Atance \& Andrew N. Meltzoff (2005). My future self: Young children's ability to anticipate and explain future states, Cognitive Development, 20(3). 341-361.

Cresswell, J. W. (1998). Qualitative Inquiry \& Research Design Choosing among five traditions. London, Sage.

Dalke H. (1998). Colour Guidelines for Bus Environment. London Transport.

Eleanor Mundy \& Camilla K. Gilmore. (2009). Children's mapping between symbolic and nonsymbolic representations of number, Journal of Experimental Child Psychology, 103(4). 490-502.

Gino YU, Roy HORAN, Michael MAMAS \& Barbara WEISSHAAR (2004). Recovering Creativity: For Personal Evolution, Industry, and Society. Journal of Youth Studies, 7(2). p1-10.

Güliz Aydin \& Ali Günay Balim. (2009). Technologically - supported mind and concept maps prepared by students on the subjects of the unit systems in our body, Procedia - Social and Behavioral Sciences, 1(1). p2838-2842.

Hill, L.H. (2004). Concept mapping in a pharmacy communications course to encourage meaningful student learning. American Journal of Pharmaceutical Education, 68(5).

Hilary Barth, Ariel Starra \& Jessic Sullivan. (2009). Children's mappings of large number words to numerosities, Cognitive Development, 24(3). p248-264.

Joseph D. Novak \& Alberto J. Cañas. (2008). The Theory Underlying Concept Maps and How to Construct and Use Them, Technical Report IHMC CmapTools 2006-01 Rev 01-2008, Florida Institute for Human and Machine Cognition, 2008.

Mary Sara Wells \& Skye G. Arthur-Banning. (2009). Mapping Out Your Success: Using Mind Maps to Evaluate Youth Development Programs. Journal of Youth Development, 4(2). p105-111.

Novak, J.D. (1998). Learning, Creating, and Using Knowledge: Concept Maps as Facilitative Tools in Schools and Corporations. Mahwah, NJ: Lawrence Erlbaum Associates.

Tony Buzan. (1997). The mind map boo. London,.

Tony Buzan \& Barry Buzan. (1996). The Mind Map Book. London: BBC Books

V. Filippakopouloua \& B. Nakos. (2009). Children and Mapping, International Encyclopedia of Human Geography, p50-57.

Wells, M.S., \& Arthur-Banning, S.G. (2007). South Carolina Children Youth and Families At-Risk (CYFAR) year end report. U.S. Department of Agriculture.

Zhe Chen. (2007). Learning to Map: Strategy Discovery and Strategy Change in Young Children, Developmental Psychology, 43(2). 386-403.

Notes

Note 1. Mind Mapping

Note 2. Concept mapping 

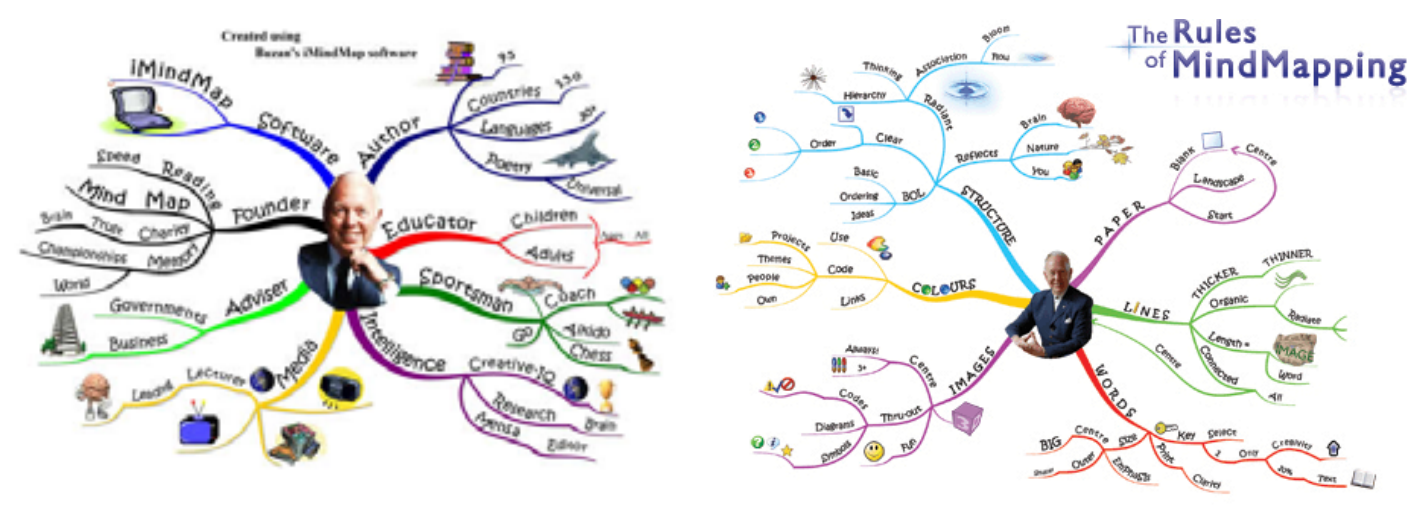

Figure 1. Mind Mapping

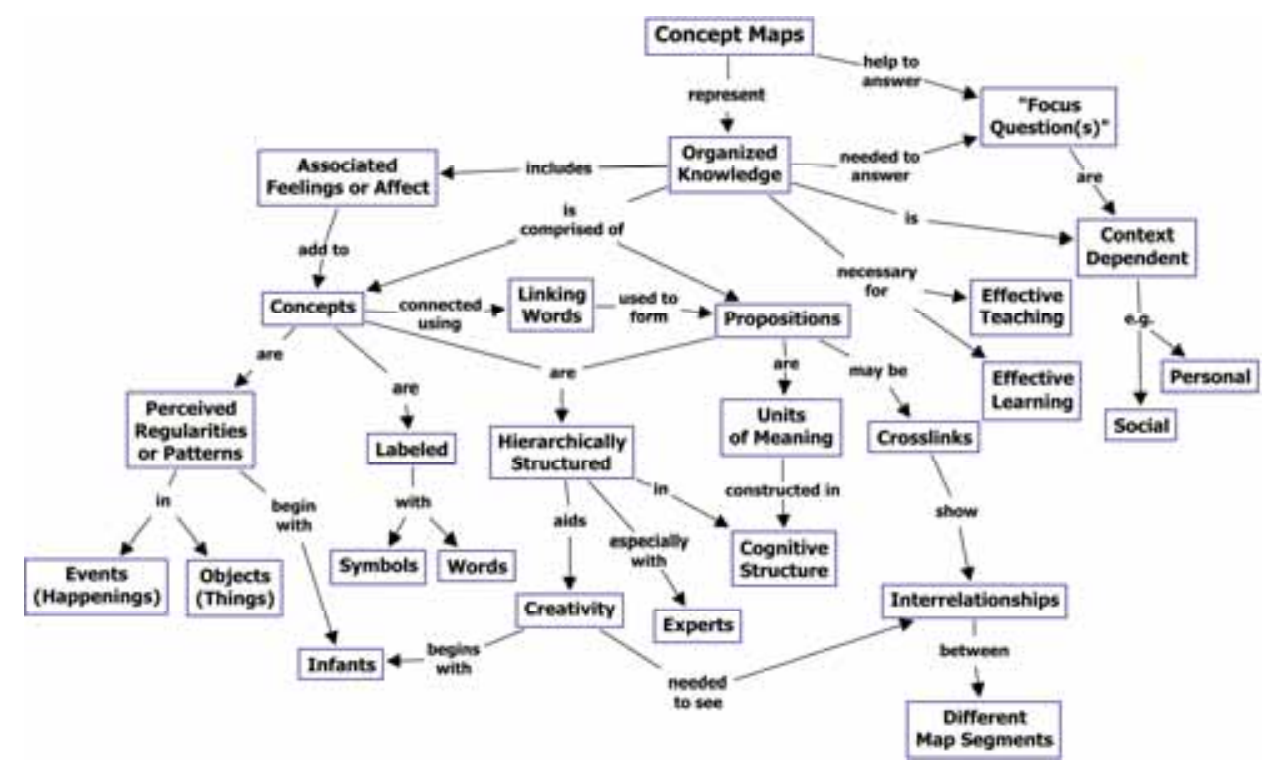

Figure 2. Concept mapping 